\title{
O papel do agente de comunicação nas relações com o esporte
}

Introdução

"O modelo B de quatro cilindros, o primeiro carro deestrada para todos os fins, merecia tornar-se conhecido. A propaganda mais eficaz eravencer uma corrida ou estabelecer um recorde" (Ford, 1926, p. 56).

AO fAZER ESTE registroem "Minhavidaeminha obra", Henry Ford, mesmo sem estabelecer conceitos teóricos, já se mostrava adepto e, pode-se dizer, um dos pioneiros da busca de resultados de mercado através da aplicação do esporte como ferramenta.

A vançando 70anos, percebe-sequeasrelações entremarketing eesportenãoficaramrestritas às idéias fordistas. Eventos e ídolos, seus feitoserepercussões ocupam hoje, no mundo inteiro, o tempo dos noticiários, as páginas da imprensa e as horas de lazer dos cidadãos. Atraem afeto e geram envolvimento, sendo motivo dereuniãoeconfraternização. Surgem, simultaneamente, como el ementos de identificação ediferenciaçãoentreindivíduos. Acima de tudo, constituem o esporte em um fato social sedimentado e estabelecido, com ampla penetração e influência no comportamento dasmaisdiversas classesesegmentos de consumidores.

Em conseqüência disto, este campo vem estabelecendo uma forte ligação com as atividades empresariais e, por isso, passa a ser um ponto de interesse obrigatório para quem estuda e trabalha tanto o marketing quanto acomunicação. Entretanto, talvez pelo fato deo esportepertencer mais ao mundo da paixão que ao da razão; mais ao das relações mágicas que ao da lógica, no mundo inteiro esta ligação vem sendo alvo de um esforço 
muito pequeno em termos teóricos.

NoBrasil, tal realidadereflete-se, também, na própria prática. Conseqüência disto, as transaçõesgeradasentreempresaseentidades esportivas acabamporter umtratamento quase amadorístico, pautando-se mais nas relações pessoais que nos objetivos de mercado propriamente ditos. Deste modo, elementos importantes como osagentes decomuni cação são colocados à margem de um negócio que, se tratado com o devido cuidado, poderia gerar não apenas uma nova área de atuação profissional, como - e principalmente negócios mais interessantes para as partes envolvidas.

É para este sentido que se dirige o foco deste artigo. Busca-se, aqui, através deumadiscussão teórica, definir o papel que este agente - o profissional de comunicação - pode desempenhar nas relações entre marketing e esporte para que passe, na prática, a participar ativamente de um negócio cujo objetivo maior é conjugar, de um lado, a vitória nos campos, nasquadras, naspistase, deoutro, o êxito sobre os concorrentes na disputa pela preferência do mercado.

\section{As relações entre marketing e esporte}

A ntes deprosseguir, porém, cabeestabelecer os limites da discussão. Assim, o esporte de que se trata aqui é aquele que não é apenas lúdico, levando em conta, isso sim, a competitividade e a performance de seus praticantes, pressupondo a existência de regras fixas e amplamente conhecidas, bem como o envolvimento de recompensas pecuniárias aos seus atores (Helal, 1990).

N o queserefereao marketing, por seu turno, longedeentrar em discussõesteóricas, buscase algo que se estabeleceu como verdade no âmbito da pesquisa nesta área do conhe cimento: o paradigmadatroca(Bartels, 1988). A partir dele, remonta-seao conceito genérico, através do qual Kotler (1972), de forma emblemática, defineo marketing como sendo um campo de atividades "especificamente preocupado com o modo como as transações são criadas, estimuladas, facilitadas e valorizadas" (p. 49).

Nestes termos, as relações entre marketing e esportesãoaqui tratadasatravésdaconsideração destes dois conceitos em um contexto de dualidade. De um lado, o intuito é oferecer o esporte e seus atores como agentes de entretenimento e lazer para um determinado público, com o pressuposto debuscar recursos que garantam tanto a manutenção das atividades quanto a remuneração dos envolvidos. Deoutro, a idéiaécolocar tais elementos à disposição de um investidor interessado em obter retorno - financeiro ou de imagem -, partindo-sedopressupostodequetal associação também encontrará correspondência junto ao segmento de público já abrangido pelas mensagens ligadas ao esporte.

Portanto, a utilização de marketing junto ao esporte, ou seja, o marketing esportivo, envolveo incentivoàrealização detransações que se inter-relacionam dualisticamente, tendo como centro o esporte e seus atores. Estes, por suavez, procuram relacionar-se, de um lado, com empresas investidoras voltadas tanto para o fomento à geração de um produto no terreno esportivo quanto para a obtenção de resultados junto ao público - e, deoutro, com o próprio público - interessado em consumir eventos e produtos do esporte em si e, conseqüentemente, sensível às mensagens daquelas organizações que demonstram uma clara identidade com suas preferências.

\section{I.1 As nuances do marketing esportivo}

Omarketingesportivo, noentanto,éumconceito que tem permitido um amplo leque de interpretaçõesao longo do tempo. Kotler (1991) situa os eventos ligados ao esporte em um grupo genérico, no capítulo em que trata das 
ações derelações públicas. Muylaert(1993), por suavez, apresentao marketing esportivo como um "primo irmão" do marketing cultural, inserindo ambos no contexto do marketing institucional, cuja principal preocupação é formar, viaderegraamédioelongo prazo, uma boa imagem corporativa, criando, na mentedo consumidor, uma impressão que distinga uma marca espećfica dentre as demais (Delozier, 1976; Gomes \& Sapiro, 1993).

Dentro disto, Schlossberg (1996) coloca que marketing esportivo é "como as empresas distinguem-senestesdias, identificando-secom heróis atléticos e suas habilidades (...), e isto funciona devido à nossa intensa afeição emocional por equipes e atletas" (p. 1). Em outras palavras, trata-se de uma união de interesses, pois, atuandosobreoladoemocional dos consumidores, ao mesmo tempo em que viabilizamentretenimento, asempresaspassam a gozar de uma boa imagem junto ao público.

Assim, a principal diferença entreo marketing esportivo e os esforços convencionais de marketing residiria no fato de o primeiro permitir que uma empresa obtenha simultaneamente um alto retorno institucional, conjugado com aquele normalmente obtido pelas campanhas de promoção de produtos. Nestes termos, ela contaria com um poderoso instrumento no que se refere à fixação demarca, a partir da ênfasepossível a benefícios e características subjetivas, reforçando ou corrigindo uma imagem projetada - atitude de grande interesse para o marketing institucional (Gracioso, 1994; Lima Gonçalves, 1994).

Já Campomar (1992), aprofundando-se na questão conceitual, acha por bem considerar o marketing esportivo como um campo de atividades com características próprias, colocando, porém, que as relações existentes entremarketingeesportecostumamenvolver, sob um mesmo rótulo, duas classes de interação que ele prefere denominar como o marketing doesporteeo esportenomarketing de uma organização.
A primeira, segundo o referido autor, abrange o uso das técnicas de marketing aplicadas à promoção deuma modal idadeesportiva junto a um determinado público, como oferta deum serviço de lazer. A segunda, por outro lado, representa um modo de relacionamento em queoesporteéintegrado àsatividadesnormais de uma empresa de bens ou serviços, sendo utilizado como uma adequação dos elementos deseumixdepromoçãoaobjetivosdecomunicação emercado determinados eestabelecidos.

Emrealidade, estadicotomia pareceum tanto artificial, apartir do momentoemqueaprática aponta para a existência, isso sim, de uma interdependência entre os dois enfoques propostos por Campomar (1992). O contexto é evidentemente dual, pois a decisão de marketing relacionada ao esporte engloba interesses tanto de uma empresa investidora quanto de um público interessado.

Emoutraspalavras, adecisão podeservoltada primeiramente ao esporte como produto, envolvendo o despertar deinteressepor uma determinada modalidade.

Depois disto, voltando-se para seu próprio mercado, a organização passa a utilizar seu marketing integrado (Kotler, 1992) para desencadear atividades quepodem abranger o patrocínio de equipes ou atletas, a criação de produtos ou a geração de eventos.

\section{A dualidade do marketing es- portivo}

A introdução do conceito da dualidade foi a opção encontrada para sobrepujar as questões teóricasquevêmobstaculizandoapossibilidade desegeneral izar eestudar asrelaçõesenvolvidas no marketing esportivo como um todo.

Paraaplicá-lo, busca-serespal do nas definições deBagozzi (1974; 1975) parao conceito detroca. Segundoele, astrocasemmarketinggeralmente são indiretas, podem envolver aspectos simbólicos ou intangíveis, e comportam a 
existência de mais de dois participantes. Indo além, o referido autor (1975) apresenta uma tipologia das trocas de marketing, definidas conforme o que segue:

a) Trocas Restritas: mantidas entre dois atores sodiaisguiadospelaidéiadereciprodidademútua;

b) Trocas Generalizadas: envolvempelomenos três agentes em relações recíprocas eunívocas, ou seja, nenhum delessebeneficia diretamente do outro, apenas indiretamente - um ator fornece ao outro, mas recebe benefícios de um terceiro; e

c) Trocas Complexas: referem-sea um sistema derelaçõesmútuasentre, nomínimo, trêspartes, sendo que cada uma delas envolve-seem pelo menos uma troca direta, enquanto o sistema como um todo está organizado como umarede interconectada de relações.

Comisto, estaidéia dereciprocidadeconduz ao que se pode chamar de marketing dual, um conceito que é agora introduzido no contexto das relações do marketing com o esporte. Este processo é análogo à relação existente entre anunciantes, agências, véculosdecomunicação e consumidores, utilizada por Bagozzi (1975) para exemplificar as trocas complexas.

Assim, da mesma forma que o anunciante adquire um espaço em uma emissora de televisão, contratando os serviços de uma agênciaparatornar possível quesuamensagem chegue aos seus consumidores, a fim de que estes concretizem a compra de seu produto, uma associação entre agentes do esporte e do marketing também pode estabelecer este tipo decadeia.

Por outra, em termos aplicados, o que ocorre, aqui, é uma troca complexa que, sob um primeiro olhar, envolve três partes interessadas, todas elas oferecendo algo para a concretização do processo e, em contrapartida, recebendo um retorno proporcional:

a) o investidor/ patrocinador: empresa produtoradeartigosesportivospropriamente ditos ou, então, fornecedora de bens ou serviços de algum modo relacionados às características atinentes ao esporte eque, por isso, possamauferir benefícioscomainteração entre as partes;

b) o esporte e seus atores: entidades ou indivíduos cuja atividade central seja gerar produtos esportivos, como equipes, clubes, associações, ligas e federações, bem como os atletas propriamente ditos;

c) o consumidor do esporte: grupo formado basicamente pelos torcedores e aficionados - sejam eles freqüentadores de eventos ou consumidoresdeinformaçãoligadaao esporte edivulgadaatravésdosmeiosdecomunicação - e pelos praticantes amadores das diversas modalidades esportivas.

Diantedessaclassificação, estatrocacomplexa pode ser exposta graficamente através da representação contida na Figura 1, a seguir:

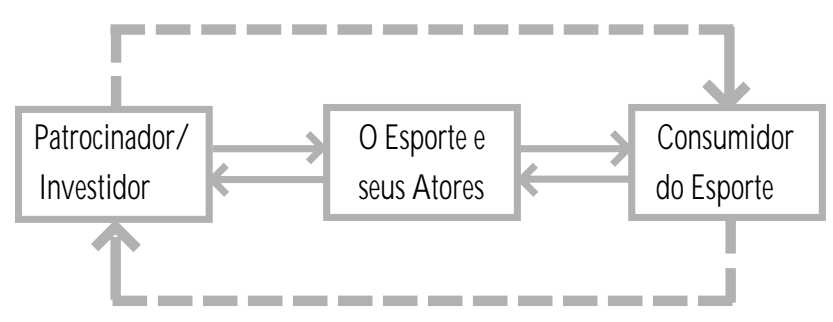

Figura1-Relação Dual entreosA gentesdo Marketing Esportivo (Teitelbaum, IIton \& Luce, Fernando B. “Marketing esportivo: uma volta de apresentação". Revista Brasileira de A dministracăa Contemporânea. Associação Nacional de Programas de PósGraduação em Administração, v. 5, p. 37-53, set. 1995, p. 47).

Feita a análise dessa representação, pode-se dizer que programas e ações de marketing ocorrem nos dois sentidos do processo, partindo sempre do elemento central: o esporte e seus atores.

Destaforma, por um doslados, o foco estáem oferecer o produto esportivo eobter, em troca, 
o respaldo dos consumidores e aficionados; no outro, o esforço évoltado para a colocação do esporte no composto promocional de um investidor que, em troca de seus recursos, passa a contar com o esporte e seus atores como veículos na condução de suas mensagens em busca da simpatia eda preferência dosreferidosconsumidores-agoracompartilhados.

Um olhar mais profundo sobrea Figura 1, no entanto, trazàtonaaausência deumelemento que, com o amadurecimento deste campo, tende a assumir um posto cada vez mais fundamental na prática do marketing esportivo.

Trata-se do agente de comunicação, cuja importância tem sido crescentementenotada na promoção das trocas realizadas entre os atores do esporte, os investidores eo públicoconsumidor.

\section{O papel do agente de comuni- ca çã o}

O agente de comunicação pode atuar basicamente de duas formas distintas.

De um lado, pode agir como intermediário entre os investidores e os atores do esporte, funcionando como uma espécie de agente matrimonial - gerando atração, casando interesseseadequando necessidadesedesejos de ambas as partes.

Deoutrolado, podeintervir na relação entreos atores do esporte e o público-consumidor do esporte, agind o como divulgador, promotor de eventos ou, ainda, como mediador, compatibilizando as ações e mensagens oriundas de entidades e atletas aos desejos emanados por seus mercados.

Comisto, o papel do agentedecomunicação nas relações do marketing esportivo ajustase à representação exposta na Figura 2, a seguir:

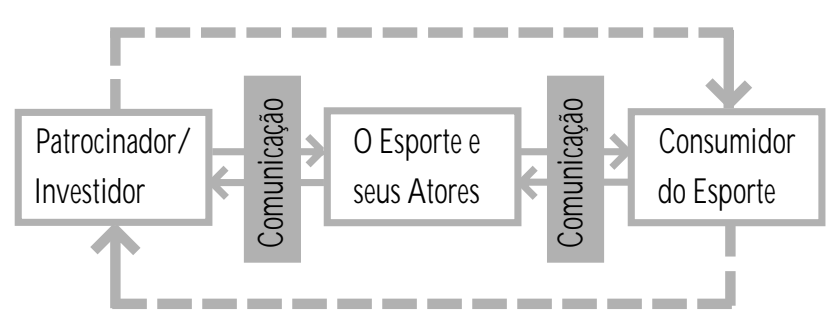

Figura 2 - 0 Papel do Agente de Comunicação nas Relações do Marketing Esportivo (Teitelbaum, Ilton \& Luce, Fernando B. "Marketing esportivo: uma volta de apresentação". Revista Brasileira de Administração Contemporânea. Associação Nacional de Programas de Pós-Graduação em Administração, v. 5, p. 37-53, set. 1995, p. 47).

Assim, retomando os conceitos teóricos anteriormente expostos e trazendo-os para o âmbito da prática, pode-se dizer que um agente de comunicação, ao atuar como intermediário entre investidores eatores do esporte, deveconcentrar seus esforços em três itens fundamentais: a) a conscientização dos investidores para o potencial deste tipo de negócio; b) a dara definição dos objetivosaseremtraçadospel osatoresdo esporte; ec) a correta elaboração do projeto.

No que se refere à conscientização, o agente deve, em primeiro lugar, buscar explicitar ao investidor o foco em imagem institucional que caracteriza o retorno viabilizado por relacionamentos entre o marketing das organizaçõeseoselementos do esporte. Sendo assim, torna-se clara a necessidade de fugir dapuraesimplescomparação entreopossível valor requerido pelo investimento, por exemplo, em um patrocínio de equipe e seu equivalente em termos de aplicação em um meio de comunicação, como o rádio ou a televisão. Enfim, cabe a este profissional esclarecer ao investidor que o prazo para obter tal retorno não é curto e que, pelo contrário, oscila entre médio e longo, pois pressupõe um período inicial deadaptação e amadurecimento.

Quanto à definição dos objetivos a serem fixadospelosatores do esporte, cabeaoagente 
decomunicaçãoadequar pretensãofinanceira ao porte do projeto e às suas inerentes possibilidades de retorno. Por outro lado, seu esforço deveser sempreno sentido de conferir a maior profissionalização possível aos procedimentos, conscientizando,ainda, entidadeseatletas dequeseuspapéisnãoserestringemao âmbito do esporte, mas que, a partir do momento em queháum investidor, el es devematuar como veículos da marca e da imagem de quem os apóia.

Por fim, ao elaborar o projeto, o agente de comunicação deveadequaro portedoinvestidor ao porte do projeto, caracterizando detalhadamente a oferta em termos de custos e benefícios, expondo possibilidades de retorno - eventos, mídia e atuação comunitária, por exemplo - e, principalmente, cuidando para apresentar cenários futuros, sem ficar restrito ao currículo de real izações passadas do atl eta ou da entidade esportiva.

Deoutro modo, ao atuar profissionalmenteem entidades esportivas, o agentedecomunicação devedaratençãoatrêsgruposbásicosdetarefas, quais sejam: a) a profissionalização de procedimentos normalmente amadores; b) a profissionalização de relações usualmente pessoais; e c) a orientação, em termos de marketing ecomunicação, aatletaseentidades.

Assimsendo, no quetangeà profissional ização de procedimentos, o agente de comunicação deveprocurar conscientizar os dirigentes sobre a importância de reger suas ações pela racionalidade, deixando um pouco de lado a puraemoção. A partir disso, devedar atençãoà tarefa de realizar um planejamento de curto, médio e longo prazo, voltando a entidade esportiva para o seu mercado, buscando viabilizar o aproveitamento dos momentos de sucesso e estabelecendo mecanismos de previsão - os únicos capazes de superar períodos dederrota.

Já no que se refere à profissionalização de relações, o profissional deve conscientizar os dirigentes-normalmenteamadores-deque a imagem da entidade deve estar acima de vaidadespessoais, oquepossibilitaa separação entre a figura do benemérito ea do investidor, viabilizando, assim, a diversificação dasfontes de receita e a conseqüente viabilização das atividades esportivas.

Por último, umatarefa das maisfundamentais: a orientação, em termos de marketing e comunicação, que deve ser dirigida a atletas e dirigentes de entidades. Cabe ao agente de comunicaçãodisseminar aculturademarketing entreosatoresdoesporte, criando, senecessário, esempredifundindo o espírito profissional algo que possibilita o atendimento dos desejos do público e permite a transmissão de uma imagem positiva para a própria entidade, para seusatletase, éclaro, paraasprópriasempresas investidoras.

\section{Comentários finais}

Com o amadurecimento das relações entreos elementos do marketing e os do esporte, a racionalidade dos negócios tende a somar forças com a emoção das disputas. A partir disso, entidades esportivas e empresas investidoras passam, cada vez mais, a sentir necessi dadedeprofissional izar seusprocedimentos conjuntos.

É nesteponto queseabreo espaço paraqueos agentes de comunicação assumam seu posto naviabilização, nagestãoena própriagarantia de manutenção dos vínculos entre empresas investidoras e atores do esporte.

Seja atuando dentro de entidades esportivas, seja como intermediários independentes, os agentes de comunicação têm um papel cada vez mais fundamental nas relações entre marketing e esporte. Cabe a eles próprios, entretanto, a tarefa de ocupar tal espaço.

Para tanto, talvez o primeiro passo seja a sua própria conscientização de que este é um novo campo que se abre. A seguir, o passo fundamental é tratar de conscientizar os 
investidores dequeesta éuma possibilidade rentável deretorno para marcaseimagens de produtos e serviços.

Tais passos talvez não sejam suficientes e definitivos, mas merecem toda a atenção. Do contrário, a intuição e o amadorismo, que há muito pedemsubstituição, continuarão como titulares em um jogo que está à feição para a dupla formada por conhecimento científico e profissionalismo.

\section{Referências}

BAGOZZI, R. "Marketing as an organized behavioral system of exchange". Journal of M arketing. Chicago, v. 38, n. 4, p. 77-81, Fall 1974.

BAGOZZI, R. "Marketing as exchange". Journal of Marketing. Chicago, v. 39, n. 4, p. 32-9, Fall 1975.

BARTELS, R. The history of marketing thought. Columbus, Publishing Horizons, 1988.

CAMPOMAR, Marcos Cortez. "Relações entre marketing e esporte". M arketing. São Paulo, v. 26, n. 233, p. 54-6, dez. 1992.

DeLOZIER, M. Wayne. The marketing communications process. New York, McGraw-Hill, 1976.

FORD, Henry. Minha vida e minha obra. Rio de Janeiro, Nacional, 1926.

GOMES, Mauro Tapias\& SAPIRO, Arão. "Imagem corporativauma vantagem competitiva sustentável". Revista de Administração de Empresas. São Paulo, v. 33, n. 6, p. 84.96, nov./ dez. 1993.

GRACIOSO, Francisco. "Propaganda Institucional a serviço da empresa". M arketing. São Paulo, n. 249, p. 31-8, fev. 1994.

HELAL, Ronaldo. 0 que é sociologia do esporte. São Paulo, Brasiliense, 1990.

KOTLER, Philip. "A generic concept of marketing". Journal of M arketing. Chicago, v. 36, n. 2, p. 46-54, Spring 1972.

KOTLER, Philip. Marketing management: analysis, planning, implementation and control. 7.ed. Englewood Cliffs, Prentice Hall, 1991

KOTLER, Philip. Administração de marketing: análise, planejamento, implementação e controle. 2.ed. São Paulo, Atlas, 1992.

LIMA GONÇALVES, JoséErnesto et al. "0 queeles pensam sobre o marketing esportivo no futebol?" RAE light. São Paulo, v. 1, n. 3, p. 16-21, jul./ ago. 1994.

MUYLAERT, Roberto. Marketing cultural \& comunicação dirigida. São Paulo, Globo, 1993.

SCHLOSSBERG, Howard. Sports marketing. Cambridge, Blakwell Publishers, 1996.

TEITELBAUM, IIton \& LUCE, Fernando B. “"Marketing esportivo: uma volta de apresentação". Revista Brasileira de Administração Contemporânea. Associação Nacional de Programas de Pós-Graduação em Administração. Rio de Janeiro, v.1, n.5, p. 37-53, set. 1995.

A na Lúcia M. da Silva

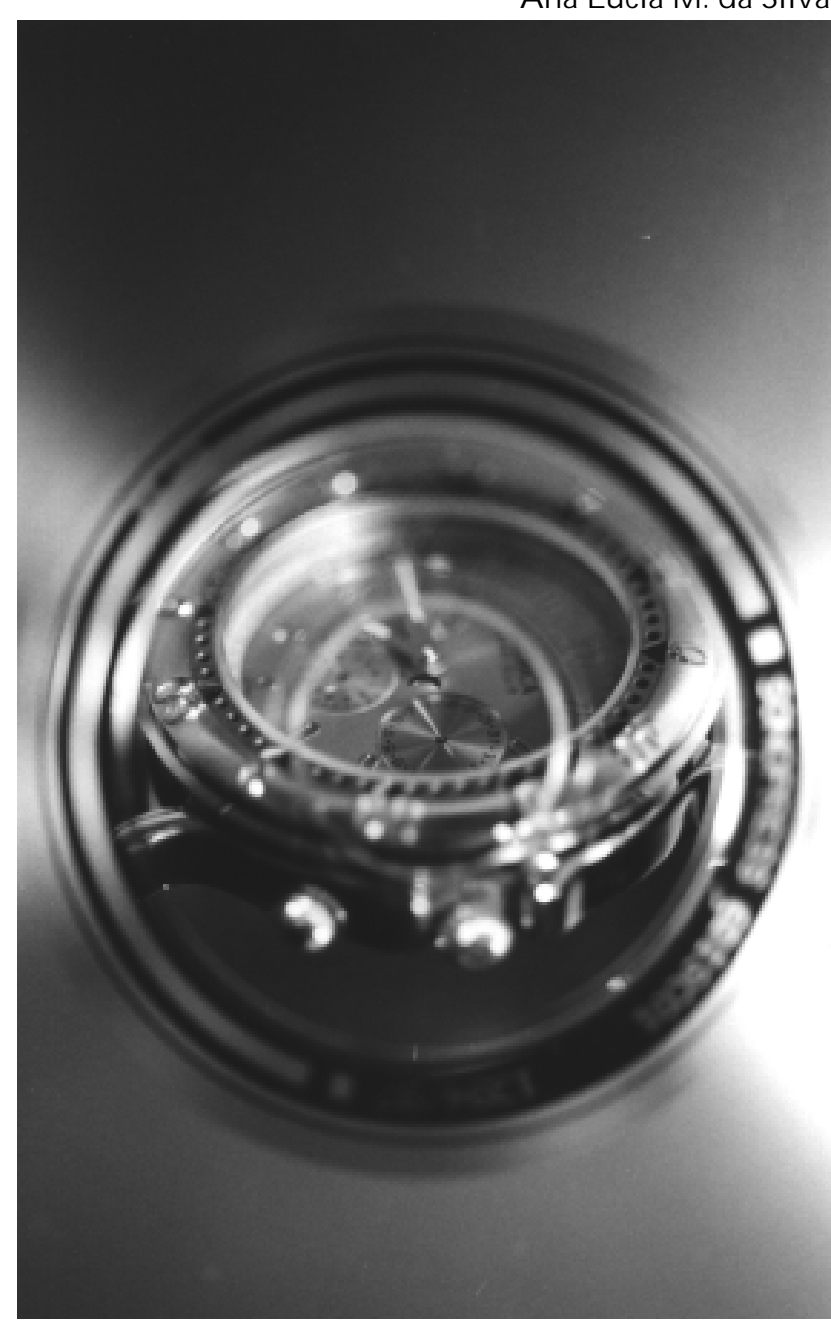

